\title{
Research Paper: The Effect of Selective Plyometric Training on the Lower Extremity Functional Per- formance Indexes of Female Athletes With Dynamic Knee Valgus
}

\author{
Farzaneh Saki $^{1}$ (D), Maryam Madhoosh ${ }^{1}$, Parisa Sedaghati ${ }^{*}$ (D) \\ 1. Department of Sport Injuries and Corrective Exercise, Faculty of Sport Sciences, Bu-Ali Sina University, Hamadan, Iran. \\ 2. Department of Sport Injuries and Corrective Exercise, Faculty of Physical Education and Sport Sciences, University of Guilan, Rasht, Iran.
}

\begin{tabular}{|c|c|}
\hline $\begin{array}{l}\text { Use vour device to scan } \\
\text { and read the article online }\end{array}$ & chation Saki F, Madhoosh M, Sedaghati P. The Effect of Selective Plyometric Training on the Lower Extremity Func- \\
\hline 口iptra & $\begin{array}{l}\text { tional Performance Indexes of Female Athletes With Dynamic Knee Valgus. Physical Treatments. 2019; 9(1):31-38. https://doi. } \\
\text { org/10.32598/PTJ.9.1.31 }\end{array}$ \\
\hline 田 & dol https://doi.org/10.32598/PTJ.9.1.31 \\
\hline
\end{tabular}

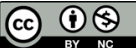

Article info:

Received: 27 May 2018

Accepted: 23 Sep 2018

Available Online: 01 Jan 2019
Keywords:

Dynamic balance, Plyometric training, Valgus

\begin{abstract}
A B S T R A C T
Purpose: Considering the high prevalence of dynamic valgus and its impact on sports performance among the female athletes, the present study aimed to examine the effect of a course of selective plyometric training on the lower extremity functional performance indexes of female athletes with dynamic knee valgus.

Methods: This research was a quasi-experimental study with a pretest-post-test design. The study population comprised the athletic girls with dynamic valgus referring to Bu-Ali Sina gymnasium of the University of Hamadan in 2018. Of them, 26 eligible girls who met the inclusion criteria were selected purposefully and then randomly assigned into experimental $\left(\right.$ Mean \pm SD age $\left.=20.25 \pm 2.34 \mathrm{y}, \mathrm{Mean} \pm \mathrm{SD} \mathrm{BMI}=21.27 \pm 2.75 \mathrm{~kg} / \mathrm{m}^{2}\right)$ and control $(\mathrm{Mean} \pm \mathrm{SD}$ age $=21.16 \pm 2.79 \mathrm{y}, \mathrm{Mean} \pm \mathrm{SD} \mathrm{BMI}=21.60 \pm 2.68 \mathrm{~kg} / \mathrm{m}^{2}$ ) groups. The experimental group performed specific plyometric training for 8 weeks, 3 times a week. Assessing the dependent variable was done using dynamic balance, Sargent and Illinois Agility tests in the pretest and post-test. The comparisons between experimental and control groups in the pretest and post-test were made by analysis of covariance and the dependent t-tests, respectively in SPSS V. 20. The significance level was set at 0.05 or lower.
\end{abstract}

Results: Considering the pretest as the covariate parameter, a significant improvement was found for total dynamic balance $(\mathrm{P}=0.005)$, anterior leg $(\mathrm{P}=0.001)$, medial-posterior leg $(\mathrm{P}=0.001)$, lateral-posterior side of right leg $(\mathrm{P}=0.028)$, vertical jump $(\mathrm{P}=0.001)$ and Illinois jumping test score $(\mathrm{P}=0.001)$ in the experimental group.

Conclusion: An improvement was seen in the dynamic balance and the movement performance of the participants with dynamic valgus after doing plyometric exercises that result in subsequent improvement in their exercise performance.

\footnotetext{
* Corresponding Author:

Parisa Sedaghati, PhD.

Address: Department of Sport Injuries and Corrective Exercise, Faculty of Physical Education and Sport Sciences, University of Guilan, Rasht, Iran. Phone: +98 (912) 2768326

E-mail: parisasedaghati@yahoo.com
} 


\section{Highlights}

- The selected plyometric training significantly improved Sargent and Illinois jumping tests.

- The selected plyometric training significantly improved dynamic balance.

\section{Plain Language Summary}

To improve the skill level of athletes, researchers always seek innovative and efficient training programs and methods. This study is presenting one of the new techniques.

\section{Introduction}

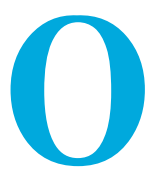

ne of the standard techniques in physical activities is the jump-landing technique that is also the common cause of Anterior Cruciate Ligament (ACL) injury. During landing, nonalignment may occur in the lower limb that is potentially due to the inefficient control of body musculoskeletal system [1]. The type of landing technique and the way each person absorb energy during landing can contribute to the incidence of ACL injury [2]. Dynamic Knee Valgus (DKV) is one of the common types of risk factors known for acute injuries and frequent use of lower extremities. In other words, it reflects the altered hip, knee, and ankle kinematics in wrong patterns of the lower limb use [3].

The control of the neuromuscular system involves the interaction between the nervous and muscular systems of the body and their components to adapt to environmental changes. Timely activation of the muscular structure can protect the joints in response to environmental stimuli, such as changes in landing surfaces [4]. The feedback mechanism allows the body to adapt to different unpredictable events by modifying muscle activity. The body also employs previous experiences to predict future events by using the feed-forward mechanism. This mechanism allows the body to prepare itself for an unexpected event. The proper activation of muscle fibers by providing the desired stiffness, as a dynamic and preventive factor, influences the undesirable loading of ACL [5].

According to studies, non-contact ACL injury usually occurs from 17 to $50 \mathrm{~ms}$ after initial ground contact. This time is too short to provide proper response feedback for correcting the wrong landing mechanics. Therefore, the importance of preparatory or feed-forwarding mechanisms becomes more evident [6]. Physical exercises and experience of an athlete correlate with the use of neuromuscular strategies and their landing technique. There- fore, the inability to respond on time during dynamic activities is associated with poor landing technique and the risk of ACL injury [2].

Men and women have different neuromuscular control strategy according to their assignment; women tend to activate more quadriceps muscles than men during tasks such as lunge maneuver [7]. Researchers examined the differences between activation ratios of the medial and lateral quadriceps in men and women after a pseudo dangerous task. They found that women activated the lateral side quadriceps more while men used a balanced ratio in activating the lateral and medial part of the quadriceps.

The unbalanced ratio of muscle activation between medial and lateral quadriceps, especially the higher activation of the lateral part, may cause higher anterior shear force and knee valgus that contributes to ACL injury [8]. According to a recent study, women with knee valgus have different gait biomechanics during dynamic activities. They showed lower knee abduction moment and knee adduction angle compared to the control. This difference can increase lateral tibiofemoral joint loading [9].

It seems that minimizing the loading of valgus can be useful in reducing the incidence of ACL. So far, many scholars have investigated the effects of ACL injury prevention exercises on the performance and neuromuscular variables of the lower extremity. However, the effect of interventional exercises on people with knee valgus, as one of the most critical risk factors for ACL injury, has been less studied.

It seems that plyometric training programs by focusing on the knee alignment and improving the landing techniques during dynamic activities, reduce the angle of knee valgus and the ground reaction forces $[10,11]$ On the other hand, this training improves feedback and feedforward activities simultaneous with matching mus- 
cle and joint receptors by applying fast forces [12]. Scholars and trainers have always sought to design effective training programs and modern methods to improve the skill level of athletes.

Meanwhile, the use of specific exercises such as plyometric training as an appropriate tool for improving physical and motor fitness, has drawn the attention of researchers. These exercises are designed to increase the sensitivity of the neuromuscular system by applying multiple stretching and acute shortening in muscles and tendons. It is believed that the effect of plyometric training is because of neuromuscular adaptation to motor unit recruitment or discharge frequency, increased feedback potential or changes in the elastic properties of the muscle [13].

Given what was discussed, it is not possible to determine which types of exercises are more effective in changing biomechanical variables, and most studies have evaluated the effectiveness of plyometric training in combination with other exercises. Few studies have investigated the effect of this training on reducing the risk factors of ACL injury, and to the best of our knowledge, there is no study on the effects of this training by performing appropriate screening and purposive selection of subjects. In this regard, this study attempted to evaluate the effect of one course of selective plyometric training on the functional performance of lower extremities of female athletes with DKV.

\section{Materials and Methods}

This research is a quasi-experimental study with pretest-post-test design and a control group. Study samples were 26 female athletes with DKV referred to sports halls of Bu-Ali Sina University in Hamedan, Iran in 2018. They were selected with purposive sampling technique and then randomly assigned to two groups of experimental $(n=14)$ and control $(n=12)$. To determine the sample size, $\mathrm{G}^{*}$ Power software was used by considering 95\% confidence interval, $80 \%$ test power, and a significance level of 0.05 , which yielded 12 samples for each group [11].

Considering the possible sample dropout, 14 subjects were determined for each group. The inclusion criteria were being $18-28$ years old, having DKV angle $>12^{\circ}$ [14], and reporting a history of performing regular sport activity for at least two years. The exclusion criteria were having a history of mechanical back pain in the past year, reporting a history of any injury in the past six months, experiencing knee and ankle injury and surgery, unwilling to cooperate during study and absence in two consecutive sessions of the interventional program.
After explaining the study objectives and method to the participants, a written consent form was signed by them.

After identifying those with DKV and completing the demographic form by the examiner, the height and weight of the subjects were measured by the examiner using a stadiometer and a scale. At baseline (pre-test phase), they all examined by the Y-Balance Test (YBT), Vertical Jump Test (VJT), and Illinois Agility Test (IAT). The control subjects continued their daily routine without performing any special exercises and without knowing the condition of other subjects. The subjects in the experimental group participated in the training program for 8 weeks (three sessions per week, each session for 45 min) under the direct supervision of the examiner. We used the training protocol used by de Marche Baldon et al. [11]. After 8 weeks, all participants again were assessed similar to the pre-test phase.

To identify DKV, single-leg landing test was used [15]. For this purpose, the subject was asked to stand with a balanced condition on a box with a height of $40 \mathrm{~cm}$, while her dominant foot was on the air (the heel was in contact with the front edge of the box) and the weight was fully tolerated by the non-dominant foot. With the examiner's command, the subject landed on the dominant leg vertically and balanced, without bending, lowering the trunk and jumping, and then maintained the position for 5 seconds. Before the test, the subjects were educated on the correct way of doing the test. After learning the test, every subject performed 3 landing trials with a 30-s interval [16].

The test has acceptable reliability for detecting DKV that has been reported as $0.88-0.91$ by Munro et al. [17]. The DKV was considered present when the examiner visually observed from the front view that the midpoint of the superior patella of the dominant leg passed the medial part of the great toe during the three trials. DKV patients were those who had knee valgus at their dominant leg during the one-leg landing test, and their knee valgus was corrected when lifting the heel. Before the test, each participant performed the warm-up exercises for $5 \mathrm{~min}$ and during the test, no feedbacks were given to correct the knee valgus.

For assessing dynamic balance, the YBT was used $[18,19]$. The intra-rater reliability of this test ranges from 0.85 to 0.91 ; its inter-rater reliability is 0.99 , and its composite reach score reliability ranges from 0.91 to 0.99 [20]. In this test, one should maintain the balance on one foot without involving the base of support and losing the balance while trying to reach three defined directions with the other foot as far as possible. The goal of reaching is to maintain a position by creating maximum 
excursion with the ability to return to the previous state. Three attempts in each direction with $15 \mathrm{~s}$ rest between each attempt were performed by each subject, and the overall score was normalized by dividing the obtained score $(\mathrm{cm})$ by the subject's leg length $(\mathrm{cm})$.

Sargent test or VJT was used for measuring lower limb strength. Many athletes need lower limb explosive power to jump from the ground up to the maximum height [21]. Because of the characteristics of some sports that are associated with multiple jumps, this test was used to assess the lower extremity strength and physical performance of the subjects. It has high reliability and reproducibility (0.84) for women [21]. The IAT was used for evaluating the agility of the subjects which is performed in different directions and angles. This test was measured using cones and a chronometer [20]. According to Pauole et al. [21] and Roozen [22], this test had acceptable validity and reproducibility for both men and women.

In this research, we used the plyometric training protocol of de Marche Baldon et al. [11] for 8 weeks in 24 sessions (Table 1). Before the beginning of training, a warm-up program including slow jogging and stretching was performed for $5 \mathrm{~min}$. The subjects were also informed about doing the tasks.

Data analysis was conducted in SPSS V. 20. The Shapiro-Wilk test was used to assess the normality of data distribution. Moreover, the Independent t test was used for comparing demographic factors, and ANCOVA for comparing the overall, anterior, posterolateral, and posteromedial stability indices of dynamic balance (right and left leg) as well as the VJT and IAT scores between groups at a significance level of $\mathrm{P}<0.05$.

\section{Results}

The normality of data distribution was tested by the Shapiro-Wilk test and the homogeneity of variances by Levene's test. According to the results, the variables of age, height, weight, body mass index (BMI), dynamic balance score and motor function had a normal distribution, and there was no significant difference between groups in terms of these variables at the pre-test phase $(\mathrm{P}>0.05)$. Table 2 presents the mean and standard deviation of demographic characteristics for participants in both groups.

According to the $t$ test results shown in Table 3, there was a significant difference $(\mathrm{P}<0.05)$ between pre-test and post-test results of subjects in the experimental group in terms of right- and left-leg overall $(\mathrm{P}=0.001)$, right-leg anterior $(\mathrm{P}=0.001)$, left-leg anterior $(\mathrm{P}=0.002)$, right-leg posteromedial $(\mathrm{P}=0.001)$, right-leg posterolateral $(\mathrm{P}=0.016)$, left-leg posteromedial $(\mathrm{P}=0.001)$, and left-leg posterolateral $(\mathrm{P}=0.007)$ stability indices, as well as the vertical jump height $(\mathrm{P}=0.001)$ and agility $(\mathrm{P}=0.0042)$. Results of ANCOVA (Table 4), by considering pre-test score as covariate, showed a significant difference $(\mathrm{P}<0.05)$ between study groups in terms of right-leg overall $(\mathrm{P}=0.005)$, left-leg overall $(\mathrm{P}=0.006)$, right-leg anterior $(\mathrm{P}=0.001)$, left-leg anterior $(\mathrm{P}=0.004)$, right-leg posteromedial $(\mathrm{P}=0.001)$, left-leg posteromedial $(\mathrm{P}=0.002)$, right-leg posterolateral $(\mathrm{P}=0.028)$, and left-leg posterolateral $(\mathrm{P}=0.003)$ stability indices, as well as vertical jump height $(\mathrm{P}=0.001)$ and agility $(\mathrm{P}=0.001)$.

\section{Discussion}

According to our study results, the overall, anterior, posterolateral and posteromedial stability indices of right and left leg, as well as the VJT and IAT scores, showed significant differences in the female athletes with DKV after 8-week plyometric training.

Table 1. The general plyometric training of de Marche Baldon [11]

\begin{tabular}{|c|c|c|c|}
\hline Phase & Weeks & Exercises & Duration \\
\hline 1 & $1-2$ & $\begin{array}{l}\text { Squat jump, lunge jump, wall jump, horizontal jump, forward-backward jumps, } \\
\text { 180-degree jump, lateral-medial jump, drop landing }\end{array}$ & $\begin{array}{l}5-8 \text { reps for each task, comple- } \\
\text { tion time between } 5 \text { and } 15 \mathrm{~s}\end{array}$ \\
\hline 2 & $3-5$ & $\begin{array}{l}\text { Squat jump, lunge jump, wall jump, triple horizontal jump, vertical jump, jump } \\
\text { over the barrier, forward-backward jump, 180-degree jump, lateral-medial jump, } \\
\text { anterior and lateral drop jump plus vertical hop }\end{array}$ & $\begin{array}{l}\text { 6-10 reps for each task, some } \\
\text { tasks in two sets, completion } \\
\text { time between } \\
\qquad 2 \times 15 \mathrm{~s}\end{array}$ \\
\hline 3 & $6-8$ & $\begin{array}{l}\text { Tuck jump, 180-degree horizontal jump, lunge jump with trunk rotation, maxi- } \\
\text { mum horizontal jump plus maximum vertical } \\
\text { jump, forward-backward, and lateral-medial hops, lateral drop landing plus } \\
\text { maximum vertical jump plus maximum horizontal jump, horizontal hop over bar- } \\
\text { riers, lateral and medial hop over barriers, single-leg drop landing plus maximum } \\
\text { vertical hop }\end{array}$ & $\begin{array}{l}\text { 4-10 reps for each task, comple- } \\
\text { tion time between } \\
5-20 \mathrm{~s}\end{array}$ \\
\hline
\end{tabular}


Table 2. Mean $\pm S D$ characteristics of the participants in the experimental and control group

\begin{tabular}{cccccc}
\hline Group & No. & Age $(\mathrm{y})$ & BMI (kg/m²) & Height (cm) & Weight (kg) \\
\hline Experimental & 14 & $20.25 \pm 2.34$ & $21.27 \pm 2.75$ & $165.71 \pm 6.877$ & $58.43 \pm 8.22$ \\
Control & 12 & $21.6 \pm 2.79$ & $21.60 \pm 2.68$ & $163.08 \pm 6.73$ & $56.75 \pm 9.5$ \\
\hline
\end{tabular}

One of the possible reasons for the improvement in their balance after plyometric training is the increase in exercise pressure by this training which is created by facilitating and synchronizing the large and fast-twitch motor units [23], stimulation of muscle spindles [24], reduction of Golgi tendon organs' inhibitory effect, and the increase in the coordination of muscles involved in co-contraction activities $[25,26]$.

By stimulating the muscle spindles, muscle contraction increases the activity of gamma efferent nerves existing in the spindles; this increased sensitivity improves joint position sense which has a significant impact on the joint control [24]. Moreover, by the challenges created in the proprioceptive receptors of lower limbs, dynamic balance is improved after performing plyometric training. This improvement can be due to the changes in the feedback of the muscle receptors which leads to the reorganization of the central nervous system and sensorimotor integration, and eventually, the change in the motor response [27].

The results of our study regarding the increased dynamic balance after plyometric training are consistent with the findings of Arazi [28] on the effects of high-intensity plyometric training on dynamic balance and agility of young male basketball players, but are against the results of Mahieu et al. [29] who compared the effect of whole-body vibration and resistance training on postural control. This consistency and inconsistency in results may be because of similarities or differences between types, intensity, and duration of exercises and individual characteristics of the samples.

Chimera et al. reported that the improvement of performance after plyometric training was more because of neural adaptations, rather than of morphologic changes [5]. The main reason for the use of plyometric training

Table 3. Comparing the mean of pretest and post-test dependent variables in the experimental and control groups

\begin{tabular}{|c|c|c|c|c|c|}
\hline Variable & Group & Pre-Test & Post-Test & $\mathbf{t}$ & Sig. \\
\hline \multirow{2}{*}{ Right side overall stability } & Experimental & $85.60 \pm 8.28$ & $118.50 \pm 8.07$ & -9.141 & $0.001 *$ \\
\hline & Control & $81.29 \pm 8.02$ & $103.49 \pm 13.28$ & -7.671 & $0.001 *$ \\
\hline \multirow{2}{*}{ Left side overall stability } & Experimental & $86.65 \pm 8.30$ & $119.41 \pm 8.41$ & -10.092 & $0.001 *$ \\
\hline & Control & $81.10 \pm 8.62$ & $103.62 \pm 13.37$ & -7.757 & $0.001 *$ \\
\hline \multirow{2}{*}{ Right-leg anterior stability } & Experimental & $80.20 \pm 6.62$ & $95.58 \pm 7.70$ & -4.506 & $0.001^{*}$ \\
\hline & Control & $80.28 \pm 5.13$ & $84.15 \pm 6.68$ & -1.684 & 0.120 \\
\hline \multirow{2}{*}{$\begin{array}{l}\text { Right-leg posteromedial } \\
\text { stability }\end{array}$} & Experimental & $85.02 \pm 10.66$ & $99.02 \pm 5.29$ & -4.339 & $0.001^{*}$ \\
\hline & Control & $77.78 \pm 13.43$ & $83.67 \pm 10.21$ & -2.132 & 0.056 \\
\hline \multirow{2}{*}{ Right-leg posterolateral stability } & Experimental & $90.89 \pm 10.35$ & $101.52 \pm 7.89$ & -2.768 & $0.016^{*}$ \\
\hline & Control & $86.05 \pm 11.39$ & $90.50 \pm 12.70$ & -1.722 & 0.113 \\
\hline \multirow{2}{*}{ Left-leg anterior stability } & Experimental & $83.44 \pm 6.80$ & $94.94 \pm 6.15$ & -3.978 & $0.002^{*}$ \\
\hline & Control & $82.95 \pm 6.08$ & $85.12 \pm 8.93$ & -0.801 & 0.440 \\
\hline \multirow{2}{*}{ Left-leg posteromedial stability } & Experimental & $89.22 \pm 10.05$ & $104.59 \pm 5.16$ & -5.581 & $0.001 *$ \\
\hline & Control & $83.41 \pm 13.36$ & $90.61 \pm 12.45$ & -2.633 & $0.023 *$ \\
\hline \multirow{2}{*}{ left-leg posterolateral stability } & Experimental & $85.60 \pm 12.35$ & $95.95 \pm 6.36$ & -3.200 & $0.007^{*}$ \\
\hline & Control & $77.01 \pm 10.47$ & $82.30 \pm 10.17$ & -2.335 & $0.040 *$ \\
\hline \multirow{2}{*}{ Agility (s) } & Experimental & $21.33 \pm 1.41$ & $20.56 \pm 1.40$ & 2.258 & $0.042^{*}$ \\
\hline & Control & $21.29 \pm 1.42$ & $22.78 \pm 1.49$ & -2.989 & $0.012^{*}$ \\
\hline \multirow{2}{*}{ Vertical jump height $(\mathrm{cm})$} & Experimental & $33.57 \pm 5.00$ & $40.10 \pm 4.57$ & -4.510 & $0.001 *$ \\
\hline & Control & $33.66 \pm 6.13$ & $33.16 \pm 6.31$ & 0.536 & 0.603 \\
\hline
\end{tabular}

* The dependent t-test significance level. 
Table 4. Comparing two study groups based on study variables by covariance results

\begin{tabular}{ccccc}
\hline Variables & Mean Square & F & Sig. & Partial Eta Squared \\
\hline Right-leg overall stability & 1137.982 & 9.855 & $0.005^{*}$ & 0.3 \\
\hline Left-leg overall stability & 1016.626 & 9.250 & $0.006^{*}$ & 0.287 \\
\hline Right-leg anterior stability & 840.438 & 17.227 & $0.001^{*}$ & 0.428 \\
\hline Right-leg posteromedial stability & 546.345 & 5.503 & $0.028^{*}$ & 0.193 \\
\hline Right-leg posterolateral stability & 1024.123 & 19.586 & $0.001^{*}$ & 0.460 \\
\hline Left-leg anterior stability & 625.411 & 10.520 & $0.004^{*}$ & 0.314 \\
\hline Left-leg posteromedial stability & 780.100 & 12.968 & $0.002^{*}$ & 0.361 \\
\hline Left-leg posterolateral stability & 630.245 & 11.506 & $0.003^{*}$ & 0.333 \\
Vertical jump height (cm) & 316.756 & 18.052 & $0.001^{*}$ & 0.605 \\
Agility $(s)$ & 32.455 & 18.618 & $0.001^{*}$ & 0.447 \\
\hline . & & &
\end{tabular}

*The ANCOVA test significance level.

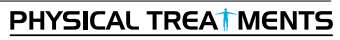

is the need for faster activation of motor units for more suitable neuromuscular adaptations [30]. Hence, the effect of plyometric training is because of neuromuscular adaptation to motor unit recruitment or discharge frequency, increased feedback potential or changes in the elastic properties of muscles and connective tissue [13].

In this regard, de Marche Baldon et al. conducted a study to evaluate the effect of plyometric training on lower limb biomechanics of 36 female athletes in two groups for 8 weeks [11]. Their results showed that plyometric training reduces knee abduction and hip adduction. Colclough et al. examined the effects of a 4-week jump training on frontal-plane projection angle in female gymnasts during single-leg landing [31].

Their results showed that doing these exercises significantly reduced frontal-plane projection angle. They suggested that jump training should be added as a part of warm-up exercises for athletes with knee injuries. Their study subjects were healthy people without DKV.

Also, our results showed a significant increase in vertical and lateral jump scores after plyometric training. Verma et al. also reported a significant increase in vertical jump height of basketball players after plyometric training [32]. McCormick et al. studied the effects of plyometrics in frontal and sagittal planes on change-ofdirection speed and power in female basketball players and reported its positive effects [33].

Myer et al. compared the effects of 8-week plyometric training and balance training on the strength and balance of 19 high-school female athletes [34]. Their results showed an increase in power and vertical jumps in both groups. In confirming these results, it can be said that jump physiologically is a plyometric movement and requires the production of explosive power, and since these exercises are repeating, they can affect the vertical jump results [35].

In another study, it was also reported that plyometric training could improve jumping performance of adolescent male and female athletes $[5,36]$. This training, by lateral to medial shift in tibiofemoral force due to an increase in gluteal force, can reduce valgus loading. This decrease, in turn, can help prevent injuries caused by abnormal knee loading [37]. Since in the exercises that somehow cause contraction with high intensity and speed, the pressure on the muscles is maximum, neuromuscular adaptation changes the mobilization pattern of motor units and cause them to act at the same time [38].

Therefore, plyometric training is superior to other exercises with respect to the neuromuscular adaptations [39]. The limitations of this study were the use of observation technique to identify individuals with $\mathrm{DKV}$, the amount of everyday activities of the subjects, and the motivational level of participants during the study. For future studies, it is recommended that video analysis be used to identify individuals with DKV among samples.

The use of special and suitable training methods for every sport is one of the most effective and commonly used methods to increase the performance of competitive athletes. Among these methods, the use of special exercises such as plyometric training, has drawn the attention of researchers as an appropriate tool for improving motor and functional performance. The athletes with DKV are more prone to injury than other athletes. Hence, it is recommended that they use this training. 


\section{Ethical Considerations}

\section{Compliance with ethical guidelines}

This study was approved by the Research Ethics Committee of Hamadan University of Medical Sciences (code: IR.UMSHA.REC.1396.841).

\section{Funding}

The present paper was extracted from the MSc thesis of Maryam Madhoosh in Department of Sport Injuries and Corrective Exercise, Faculty of Sport Sciences, Bu -Ali Sina University.

\section{Authors' contributions}

All authors contributed in designing, running, and writing all parts of the research.

\section{Conflict of interest}

The authors declared no conflict of interest.

\section{References:}

[1] Ambegaonkar JP, Shultz SJ, Perrin DH, Schmitz RJ, Ackerman TA, Schulz MR. Lower body stiffness and muscle activity differences between female dancers and basketball players during drop jumps. Sports Health. 2011; 3(1):89-96. [DOI:10.1177/1941738110385998] [PMID] [PMCID]

[2] Cortes N, Onate J, Abrantes J, Gagen L, Dowling E, Van Lunen B. Effects of gender and foot-landing techniques on lower extremity kinematics during drop-jump landings. Journal of Applied Biomechanics. 2007; 23(4):289-99. [DOI:10.1123/jab.23.4.289] [PMID]

[3] Maykut JN, Taylor-Haas JA, Paterno MV, DiCesare CA, Ford KR. Concurrent validity and reliability of $2 \mathrm{~d}$ kinematic analysis of frontal plane motion during running. International Journal of Sports Physical Therapy. 2015; 10(2):136-46. [PMID] [PMCID]

[4] Cowley HR, Ford KR, Myer GD, Kernozek TW, Hewett TE. Differences in neuromuscular strategies between landing and cutting tasks in female basketball and soccer athletes. Journal of Athletic Training. 2006; 41(1):67-73. [PMID] [PMCID]

[5] Chimera NJ, Swanik KA, Swanik CB, Straub SJ. Effects of plyometric training on muscle-activation strategies and performance in female athletes. Journal of Athletic Training. 2004; 39(1):24-31. [PMID] [PMCID] ]

[6] Zebis MK, Andersen LL, Bencke J, Kjær M, Aagaard P. Identification of athletes at future risk of anterior cruciate ligament ruptures by neuromuscular screening. The American Journal of Sports Medicine. 2009; 37(10):1967-73. [DOI:10.1177/0363546509335000] [PMID]
[7] Beutler AI, Sarah J, Marshall SW, Padua DA, Boden BP. Muscle strength and qualitative jump-landing differences in male and female military cadets: The jump-ACL study. Journal of Sports Science \& Medicine. 2009; 8:663-71. [PMID] [PMCID]

[8] Myer GD, Ford KR, Hewett TE. The effects of gender on quadriceps muscle activation strategies during a maneuver that mimics a high ACL injury risk position. Journal of Electromyography and Kinesiology. 2005; 15(2):181-9. [DOI:10.1016/j.jelekin.2004.08.006] [PMID]

[9] Hoch MC, Weinhandl JT. Effect of valgus knee alignment on gait biomechanics in healthy women. Journal of Electromyography and Kinesiology. 2017; 35:17-23. [DOI:10.1016/j. jelekin.2017.05.003] [PMID]

[10] Colclough A, Munro AG, Herrington LC, McMahon JJ, Comfort P. The effects of a four week jump-training program on frontal plane projection angle in female gymnasts. Physical Therapy in Sport. 2018; 30:29-33. [DOI:10.1016/j. ptsp.2017.11.003] [PMID]

[11] Baldon Rde M, Moreira Lobato DF, Yoshimatsu AP, dos Santos AF, Francisco AL, Pereira Santiago PR, et al. Effect of plyometric training on lower limb biomechanics in females. Clinical Journal of Sport Medicine. 2014; 24(1):44-50. [DOI:10.1097/01.jsm.0000432852.00391.de] [PMID]

[12] Hewett T, Zazulak B, Myer G, Ford K. A review of electromyographic activation levels, timing differences, and increased anterior cruciate ligament injury incidence in female athletes. British Journal Of Sports Medicine. 2005; 39(6):34750. [DOI:10.1136/bjsm.2005.018572] [PMID] [PMCID]

[13] Vissing K, Brink M, Lønbro S, Sørensen H, Overgaard K, Danborg K, et al. Muscle adaptations to plyometric vs. resistance training in untrained young men. The Journal of Strength \& Conditioning Research. 2008; 22(6):1799-810. [DOI:10.1519/JSC.0b013e318185f673] [PMID]

[14] Herrington L, Munro A. Drop jump landing knee valgus angle: Normative data in a physically active population. Physical Therapy in Sport. 2010; 11(2):56-9. [DOI:10.1016/j. ptsp.2009.11.004] [PMID]

[15] Ludwig O, Simon S, Piret J, Becker S, Marschall F. Differences in the dominant and non-dominant knee valgus angle in junior elite and amateur soccer players after unilateral landing. Sports. 2017; 5(1):14. [DOI:10.3390/sports5010014] [PMID] [PMCID]

[16] Russell KA, Palmieri RM, Zinder SM, Ingersoll CD. Sex differences in valgus knee angle during a single-leg drop jump. Journal of Athletic Training. 2006; 41(2):166-71. [PMID] [PMCID]

[17] Munro A, Herrington L, Carolan M. Reliability of 2-dimensional video assessment of frontal-plane dynamic knee valgus during common athletic screening tasks. Journal of Sport Rehabilitation. 2012; 21(1):7-11. [DOI:10.1123/ jsr.21.1.7] [PMID]

[18] Chimera NJ, Smith CA, Warren M. Injury history, sex, and performance on the functional movement screen and $\mathrm{Y}$ balance test. Journal of Athletic Training. 2015; 50(5):475-85. [DOI:10.4085/1062-6050-49.6.02] [PMID] [PMCID]

[19] Smith CA, Chimera NJ, Warren M. Association of y balance test reach asymmetry and injury in division I athletes. Medi- 
cine and Science in Sports and Exercise. 2015; 47(1):136-41. [DOI:10.1249/MSS.0000000000000380] [PMID]

[20] Miller MG, Herniman JJ, Ricard MD, Cheatham CC, Michael TJ. The effects of a 6-week plyometric training program on agility. Journal of Sports Science \& Medicine. 2006; 5(3):459-65. [PMID] [PMCID]

[21] Pauole K, Madole K, Garhammer J, Lacourse M, Rozenek R. Reliability and validity of the T-test as a measure of agility, leg power, and leg speed in college-aged men and women. The Journal of Strength \& Conditioning Research. 2000; 14(4):443-50. [DOI:10.1519/00124278-200011000-00012]

[22] Roozen M. Illinois agility test. NSCA's Performance Training Journal. 2004; 3(5):5-6.

[23] Trowbridge C, Ricard M, Knight K, Hopkins J, Draper D, Hilton S. The effects of strength and plyometric training on joint position and joint moments of the female knee. Journal of Orthopaedic \& Sports Physical. 2007; 37(2):A25.

[24] Docherty CL, Moore JH, Arnold BL. Effects of strength training on strength development and joint position sense in functionally unstable ankles. Journal of Athletic Training. 1998; 33(4):310-4. [PMID] [PMCID]

[25] Dhahbi W, Chaabene H, Chaouachi A, Padulo J, G Behm D, Cochrane J, et al. Kinetic analysis of push-up exercises: A systematic review with practical recommendations. Sports Biomechanics. 2018:1-72. [DOI:10.1080/14763141.2018.1512 149] [PMID]

[26] Smith BI, Curtis D, Docherty CL. Effects of hip strengthening on neuromuscular control, hip strength, and self-reported functional deficits in individuals with chronic ankle instability. Journal of Sport Rehabilitation. 2018; 27(4):364-70. [DOI:10.1123/jsr.2016-0143] [PMID]

[27] Young WK, MetzlJD. Strength training for the young athlete. Pediatric Annals. 2010; 39(5):293-9. [DOI:10.3928/0090448120100422-10] [PMID]

[28] Arazi H, Asadi A. Effects of high-intensity plyometric training on dynamic balance, agility, vertical jump and sprint performance in young male basketball players. Journal of Sport and Health Research. 2012; 4(1):35-44.

[29] Mahieu NN, Witvrouw E, van de Voorde D, Michilsens D, Arbyn $\mathrm{V}$, van den Broecke W. Improving strength and postural control in young skiers: Whole-body vibration versus equivalent resistance training. Journal of Athletic Training. 2006; 41(3):286-93. [PMID] [PMCID]

[30] Bompa T, Buzzichelli C. Periodization training for sports. Illinois: Human kinetics; 2015.

[31] Colclough A, Munro A, Herrington L, McMahon J, Comfort $\mathrm{P}$. The effects of a four week jump-training program on frontal plane projection angle in female gymnasts. Physical Therapy in Sport. 2018; 30:29-33. [DOI:10.1016/j. ptsp.2017.11.003] [PMID]

[32] Verma C, Subramanium L, Krishnan V. Effect of plyometric training on vertical jump height in high school basketball players: A randomised control trial. International Journal of Medical Research \& Health Sciences. 2015; 4(1):7-12. [DOI:10.5958/2319-5886.2015.00002.8]

[33] McCormick BT, Hannon JC, Newton M, Shultz B, Detling $\mathrm{N}$, Young WB. The effects of frontal-and sagittal-plane plyometrics on change-of-direction speed and power in adolescent female basketball players. International Journal of Sports Physiology and Performance. 2016; 11(1):102-7. [DOI:10.1123/ijspp.2015-0058] [PMID]

[34] Myer GD, Ford KR, Brent JL, Hewett TE. The effects of plyometric vs. dynamic stabilization and balance training on power, balance, and landing force in female athletes. Journal of Strength and Conditioning Research. 2006; 20(2):345-53. [DOI:10.1519/00124278-200605000-00019] [PMID]

[35] Markovic G. Does plyometric training improve vertical jump height? A meta-analytical review. British Journal of Sports Medicine. 2007; 41(6):349-55. [DOI:10.1136/ bjsm.2007.035113] [PMID] [PMCID]

[36] Kotzamanidis C, Chatzopoulos D, Michailidis C, Papaiakovou G, Patikas D. The effect of a combined high-intensity strength and speed training program on the running and jumping ability of soccer players. The Journal of Strength \& Conditioning Research. 2005; 19(2):369-75. [DOI:10.1519/00124278-200505000-00022] [PMID]

[37] Czasche MB, Goodwin JE, Bull AM, Cleather DJ. Effects of an 8-week strength training intervention on tibiofemoral joint loading during landing: A cohort study. BMJ Open Sport \& Exercise Medicine. 2018; 4(1):e000273. [DOI:10.1136/ bmjsem-2017-000273] [PMID] [PMCID]

[38] Ross A, Leveritt M, Riek S. Neural influences on sprint running. Sports Medicine. 2001; 31(6):409-25. [DOI:10.2165/00007256-200131060-00002] [PMID]

[39] Åstrand P-O, Rodahl K, Dahl HA, Strømme SB. Textbook of work physiology: Physiological bases of exercise. Illinois: Human Kinetics; 2003. 